\title{
INVESTIGANDO A PRÁTICA ESCOLAR NO CONTEXTO DA DIDÁTICA E ORGANIZAÇÃO DO TRABALHO EDUCATIVO
}

Claiton José Grabauska

cgrabauska@mail.ufsm.br

Elena Maria Mallmann

emallmann@mail.ufsm.br

Fábio da Purificação de Bastos

fbastos@c.ufsm.br

Gionara Tauchen

gionara@mail.ufsm.br

\section{RESUMO}

A discussão empreendida nesse artigo coloca em evidência as contribuições da ação investigativo-escolar estratégica no contexto da formação de professores. Decorrem desta investigação, a programação, implementação e monitoramento de práticas escolares compartilhadas através de registros, reflexões e auto-reflexões que visam uma sistemática transformação do trabalho docente.

\section{PROBLEMATIZAÇÕES INICIAIS}

Quando a prática docente escolar torna-se uma prática investigativa? Como podemos orientar esta prática? Quais os problemas que nos propomos a resolver? Como estes problemas são relacionados com os temas educativos?

Entendemos que uma situação educativa escolar melhor informada exige mudanças na linguagem e nos discursos utilizados nesta, nas atividades e práticas que a caracterizam e, conseqüentemente, nas relações sociais e das formas de organização envolvidas. Dito isso, quais as categorias consideradas básicas para a compreensão de qualquer situação educativa escolar?

Compreendemos que uma situação educativa pode ser melhor entendida a partir das interações entre professores, estudantes, tema e contexto. Para facilitar esta interação podemos criar uma estrutura sistemática para orientar 0 processo ensino/aprendizagem onde as categorias básicas mencionadas estivessem mutuamente relacionadas.

Compartilhando deste entendimento, organizamos e desenvolvemos, durante o primeiro semestre de 2003, na disciplina de Didática e Organização do Trabalho 
Educativo (DOTE, PPGE/CE), parte de um projeto de investigação-ação escolar. Organizamos, com a participação dos discentes e discentes, uma estrutura sistemática que nos permitiu examinar, discutir e avaliar as nossas estratégias didáticas ao longo do semestre, orientadas por questões elaboradas sobre a relação entre as categorias acima citadas.

\section{ORGANIZANDO E CONSTRUINDO ESTRATÉGIAS ESCOLARES}

Utilizamos, como suporte de ensino-aprendizagem investigativo, um ambiente construído para internet, projeto intitulado Ambiente Multimídia para Educação Mediada por Computador (AMEM). Este fornece ferramentas automáticas para customização dos materiais didáticos, inclusive na forma de desafio, melhor solução no momento e desafio mais amplo, organizando o processo de aprendizagem em três momentos pedagógicos. $\mathrm{O}$ ambiente utiliza como base didático-metodológico conceitos e teorias educacionais dialógicas-problematizadoras associados à tecnologia da informação.

Tecnicamente, ao acessar o endereço <http://amem.ce.ufsm.br> é mostrada a tela inicial que contém as explicações sobre o projeto AMEM, bem como a barra para acessar o ambiente e, na seqüência, o módulo Disciplinas, onde o aluno deverá escolher aquela em que está matriculado. Dessa forma, estes têm acesso a Lista de Atividades, com o nome, data/hora de início, existência e encerramento ou não de Tarefas extra-classe e Atividade de colaboração.

Através deste recurso, os alunos têm acesso ao pré-planejamento, a bibliografia que será utilizada em aula, bem como um espaço aberto para as atividades de colaboração (tarefa prospectiva) e nas Tarefas extra-classe (tarefa retrospectiva). $O$ quadro abaixo, mostra o caráter retrospectivo e prospectivo dos momentos que compõem a investigação-ação educacional. 


\begin{tabular}{|c|l|l|}
\hline MOMENTOS & \multicolumn{1}{|c|}{$\begin{array}{c}\text { CARÁTER } \\
\text { RETROSPECTIVO }\end{array}$} & \multicolumn{1}{c|}{$\begin{array}{c}\text { CARÁTER } \\
\text { PROSPECTIVO }\end{array}$} \\
\hline PLANEJAMENTO & $\begin{array}{l}\text { Em relação à reflexão } \\
\text { sobre a "situação" em que } \\
\text { foi } \\
\text { concebido/reconstruído. }\end{array}$ & $\begin{array}{l}\text { Em relação ação e às } \\
\text { atividades de } \\
\text { colaboração. }\end{array}$ \\
\hline AÇÃO & $\begin{array}{l}\text { Em relação à reflexão } \\
\text { acerca do planejamento. }\end{array}$ & $\begin{array}{l}\text { Em relação à observação } \\
\text { e as reflexões futuras } \\
\text { sobre os "erros" e } \\
\text { "acertos" da ação. }\end{array}$ \\
\hline OBSERVAÇÃO & $\begin{array}{l}\text { Em relação à ação } \\
\text { realizada. }\end{array}$ & $\begin{array}{l}\text { Em relação à reflexão } \\
\text { sobre o realizado. }\end{array}$ \\
\hline REFLEXÃO & $\begin{array}{l}\text { Em relação às ações } \\
\text { desenvolvidas até o } \\
\text { momento - tarefas extra- } \\
\text { classe. }\end{array}$ & $\begin{array}{l}\text { Em relação ao futuro } \\
\text { replanejamento. }\end{array}$ \\
\hline
\end{tabular}

(inspirado em Tauchen et al. 2001, p. 102)

O planejamento de uma das aulas, teve como questão orientadora para colaboração o seguinte questionamento: Qual a justificativa para a construção da preocupação temática (instrumento de pesquisa), sob a forma de matriz dialógica-problematizadora, no contexto da educação dialógica problematizadora e investigação-ação escolar?

Recebemos, através do ambiente, as contribuições dos alunos. Algumas, apresentadas a seguir:

Justifica-se a preocupação temática uma vez que se espera que o tema proposto atinja as aspirações do grupo de pessoas que fazem parte do contexto educacional. E, para isso, faz-se necessário reorientar temas para a compreensão da situação educativa. A preocupação temática surge de um diagnóstico prévio da situação educativa, através de observações e questões acerca da situação em que se está trabalhando.

(...) possibilita ao educador visualizar melhor o diagnóstico feito e os temas mais significativos encontrados no diálogo entre educando- educando e educando- educador, sua linguagem, suas idéias, seu meio sócio-cultural e histórico. Ao tabular estes dados na tábua de informações, o educador terá uma visão mais ampla destes pontos e serão contemplados no projeto colaborativo de investigação-ação.Ela também possibilita ao educador rever sua proposta sempre que achar necessário e refazê-la adequando pontos não alcançados. 
Perpassa, nos escritos, a preocupação com o grupo, isto, é de investigar temas que tenham pertinência para o coletivo envolvido. Percebemos que ao pensar o cotidiano, e erguê-lo à condição de tempo e espaço privilegiado de produção da existência, revelamos as concepções, crenças e valores que dão sentido e direção ao nosso trabalho educativo, considerando-o de modo complexo. Implica em não poder dissociar a teoria em si das situações compreendidas por seu intermédio.

A partir da leitura das colaborações, o planejamento da aula seguiu a seguinte estrutura:

30 min - Desafio Inicial:

Tendo como referência a bibliografia indicada, conceitue preocupação temática.

60 min - Melhor solução escolar no momento:

Elaboração, em grupos, de uma linha da matriz dialógico-problematizadora de DOTE e diálogo-problematizador sobre a produção.

30 min - Desafio mais Amplo:

Qual a função das questões de pesquisa, presentes em cada elemento da matriz dialógico problematizadora elaborada?

Após o primeiro momento da aula, dividimos a turma em grupos e trabalhamos diretamente no ambiente multimídia, problematizando as categorias (professores, estudantes, tema de estudo e contexto) que compõem as linhas da Matriz dialógicaproblematizadora. Assim, construímos dezesseis elementos matriciais que se comportam como questões de pesquisa servindo para prismatização de nossas programações, implementações, registros e reflexões (Mallmann, 2003, p. 09).

\begin{tabular}{|l|l|l|l|l|}
\hline & $\begin{array}{l}\text { (A) } \\
\text { Professores }\end{array}$ & $\begin{array}{l}\text { (B) } \\
\text { Estudantes }\end{array}$ & (C) Tema & (D) Contexto \\
\hline $\begin{array}{l}\text { Professore } \\
\text { s }\end{array}$ & $\begin{array}{l}\text { [A1] Como os } \\
\text { professores } \\
\text { constroem e } \\
\text { compartilham } \\
\text { suas auto- } \\
\text { reflexões }\end{array}$ & $\begin{array}{l}\text { [B1] Qual a } \\
\text { compreensão } \\
\text { dos estudantes } \\
\text { em relação à } \\
\text { disciplina tendo } \\
\text { em vista a } \\
\text { nomenclatura }\end{array}$ & $\begin{array}{l}\text { [C1] Até que } \\
\text { ponto o } \\
\text { trabalho na } \\
\text { DOTE vem } \\
\text { contribuindo no } \\
\text { fortalecimento } \\
\text { do processo de }\end{array}$ & $\begin{array}{l}\text { [D1] O AMEM } \\
\text { possibilita o } \\
\text { redimensionament } \\
\text { o da prática dos } \\
\text { professores nas } \\
\text { aulas na }\end{array}$ \\
\hline
\end{tabular}




\begin{tabular}{|c|c|c|c|c|}
\hline & $\begin{array}{l}\text { sobre a } \\
\text { disciplina? }\end{array}$ & $\begin{array}{l}\text { utilizada pelos } \\
\text { professores? }\end{array}$ & $\begin{array}{l}\text { ensino- } \\
\text { aprendizagem } \\
\text { da formação } \\
\text { escolar- } \\
\text { continuada de } \\
\text { professores? }\end{array}$ & $\begin{array}{l}\text { perspectiva da IAE } \\
\text { e EDP? }\end{array}$ \\
\hline $\begin{array}{l}\text { (2) } \\
\text { Estudantes }\end{array}$ & $\begin{array}{l}\text { [A2] De que } \\
\text { forma os } \\
\text { estudos } \\
\text { sobre IAE - } \\
\text { EDP podem } \\
\text { contribuir } \\
\text { com o } \\
\text { fortaleciment } \\
\text { o da } \\
\text { formação } \\
\text { escolar } \\
\text { continuada } \\
\text { dos } \\
\text { estudantes, } \\
\text { de modo a } \\
\text { auxiliá-los na } \\
\text { compreensão } \\
\text { e ação nos } \\
\text { seus } \\
\text { contextos } \\
\text { específicos? }\end{array}$ & $\begin{array}{l}\text { [B2] Quais as } \\
\text { dificuldades } \\
\text { que encontras } \\
\text { na DOTE? }\end{array}$ & $\begin{array}{l}\text { [C2] O tema em } \\
\text { estudo é } \\
\text { significativo } \\
\text { para os } \\
\text { estudantes? }\end{array}$ & \begin{tabular}{|l|} 
[D2] As aulas \\
contribuem para \\
apreensão dos \\
conceitos tratados?
\end{tabular} \\
\hline $\begin{array}{l}\text { (3) Tema de } \\
\text { Estudo }\end{array}$ & $\begin{array}{l}\text { [A3] Os } \\
\text { professores } \\
\text { que atuam na } \\
\text { DOTE estão } \\
\text { preocupados } \\
\text { com } \\
\text { inovação, em } \\
\text { termos de } \\
\text { conteúdos } \\
\text { escolares? }\end{array}$ & \begin{tabular}{|l|} 
[B3] Os \\
estudantes \\
estão \\
buscando \\
novos \\
conhecimentos \\
, no âmbito da \\
DOTE, ou \\
novas formas \\
de trabalhar a \\
docência?
\end{tabular} & $\begin{array}{l}\text { [C3] A IAE e a } \\
\text { EDP sustentam } \\
\text { o diálogo- } \\
\text { problematizado } \\
\text { r na DOTE? }\end{array}$ & $\begin{array}{l}\text { [D3] A } \\
\text { DOTE/PPGE é } \\
\text { propícia para } \\
\text { desenvolver este } \\
\text { tema (IAE-EDP e } \\
\text { EP-EAD)? }\end{array}$ \\
\hline $\begin{array}{l}\text { (4) } \\
\text { Contexto }\end{array}$ & $\begin{array}{l}\text { [A4] Como os } \\
\text { professores } \\
\text { de DOTE } \\
\text { trabalham } \\
\text { neste espaço } \\
\text { escolar? }\end{array}$ & $\begin{array}{l}\text { [B4] Como os } \\
\text { estudantes da } \\
\text { DOTE vão } \\
\text { transitar pela } \\
\text { EP e EAD com } \\
\text { o apoio do } \\
\text { AMEM? }\end{array}$ & $\begin{array}{l}\text { [C4] A IAE-EDP } \\
\text { pode contribuir } \\
\text { culturalmente } \\
\text { com a } \\
\text { DOTE/PPGE? }\end{array}$ & $\begin{array}{l}\text { [D4] Quais } \\
\text { transformações } \\
\text { escolares possíveis } \\
\text { na DOTE/PPGE, } \\
\text { tendo em vista EP- } \\
\text { EAD e IAE-EDP, } \\
\text { no decorrer das } \\
\text { aulas? }\end{array}$ \\
\hline
\end{tabular}


PROFESSORES: Docentes da disciplina DOTE e Mestrandos do PPGE/UFSM.

ESTUDANTES: Mestrandos do PPGE matriculados em DOTE no semestre 01/03, alunos especiais do PPGE/UFSM (professores do NEJA) e alunos ouvintes.

TEMA DE ESTUDO: A DOTE na formação escolar-continuada de professores, na perspectiva da IAE-EDP (nos âmbitos da educação presencial e educação a distância).

CONTEXTO: Aulas de DOTE no PPGE/UFSM em 01/03 (com suporte da educação a distância no AMEM).

A elaboração da Matriz dialógico-problematizadora nos auxiliou na definição dos questionamentos que orientaram a prática docente. Esta organização cria uma estrutura sistemática que facilita a discussão da preocupação temática entre os docentes servindo, também, como ponto de partida para negociar um projeto de investigação-ação (Kemmis \& Mctaggart, 1988, p. 125).

Cada uma das questões expostas na matriz facilita o direcionamento da reflexão sobre as interações que ocorrem entre as categorias, ampliando a nossa visão sobre o ensino. Segundo Kemmis \& Mctaggart (1988, p. 128), nos ajudará a tomar em consideração como se relacionam a ação individual e a ação cultural na formação da situação, e como poderiam ser modificadas, reconstruídas ou reformadas.

Adotamos, também, "diários de campo" ou "diários de bordo" para registrar nossas observações durante o desenvolvimento da aula. Eis nossas impressões sobre a atividade realizada:

Construir as questões da Matriz dialógica-problematizadora foi um desafio. Primeiro, porque nunca tínhamos feito este tipo de atividade com os alunos; segundo, porque eu precisava, a todo instante, situar as professoras quanto ao tema e o contexto. (Gionara).

Essa atividade funcionou melhor do que eu esperava! Todos os estudantes se envolveram muito no diálogo e construção de cada uma das quatro questões. Tiveram dúvidas quanto à validade desse procedimento ao longo da disciplina e, principalmente, quanto à sua participação na elaboração do mesmo. Por isso, tive que retomar várias vezes qual a função da Matriz dialógico-problematizadora ao longo da programação e aulas de DOTE. Funcionou, também, como atividade em grupo e no que se refere à atuação dos professores (Elena). 
Nossos escritos contemplam o processo de construção realizado através da interação dialógica entre os sujeitos que são co-responsáveis pelo processo ensinoaprendizagem. As problematizações que deram corpo à Matriz foram retomadas durante a elaboração dos planejamentos das aulas seguintes e norteadoras do nosso olhar sobre o processo ensino-aprendizagem realizado na DOTE. Nossas autoreflexões, registradas nos nossos diários, compartilhadas durante os replanejamentos, possibilitaram uma reflexão mais sistemática e rigorosa sobre o processo vivenciado ao longo do semestre.

\section{ALGUMAS CONSIDERAÇÕES}

A partir da investigação da nossa ação docente podemos problematizá-la, ampliar nossa compreensão teórica sobre esta e nossa formação. Para tanto, precisamos adotar concepções e métodos de investigação participativos, colaborativos pois, o foco da nossa investigação localiza-se nas situações educativas e nas autocompreensões que os sujeitos têm sobre estas, buscando o desenvolvimento de um conhecimento mais sistemático e profundo das situações e problemas particulares, elaborando ações estratégicas compartilhadas para transformá-las.

A elaboração dessas estratégias está relacionada, também, a uma base teórica compartilhada pelos sujeitos, enraizada dentro de uma opção filosófica e epistemológica, levada a cabo através de processos sociais de investigação. Apresenta, porém, um aspecto privado. Os sujeitos também extraem suas conclusões sobre cada situação vivenciada, podendo auto-refletir e atuar de forma privada sobre seu modo de ver a teoria e a prática. Porém, o desenvolvimento destas teorias e práticas depende da participação consciente dos sujeitos numa prática social (Carr, 1995, p. 35).

É importante pontuar também, o livre acesso aos registros, dados, interpretações e achados do grupo. Um processo estabelecido pela fidelidade a uma rede ética mutuamente pactuada, a qual governa a coleta, uso e divulgação dos dados. O diário na prática escolar foi um instrumento didático que possibilitou clarear as idéias sobre o ensino na medida que compartilhamos com nossos colegas nossos êxitos e desafios. Ocorreu, nos momentos de planejamento, um esforço retrospectivo que oportunizou o estabelecimento das relações entre a teoria e prática educacional, 
redimensionando as interações e reflexões entre os sujeitos (educadores e educandos). Segundo De Bastos \& Miquelin (2002, p. 02),

\begin{abstract}
Estamos compreendendo a investigação-ação escolar como uma ação investigativo-escolar estratégica donde decorre a programação de práticas escolares, sua implementação, o monitoramento dessas através de registros, reflexões e auto-reflexões para uma sistemática transformação em forma de reprogramações.
\end{abstract}

Este processo, apoiado no AMEM, comporta os ciclos da investigação-ação escolar, garantindo que os professores, no processo ensino-aprendizagem, estejam constantemente monitorando e refletindo sobre suas práticas escolares, de modo a transformá-las.

A sistematização dos alunos nas atividades de colaboração e extra-classe permitiunos investigar a compreensão destes sobre os temas estudados, tentando monitorar suas concepções antes, durante e depois da aula, isto é, também nos momentos a distância. Neste processo sistemático, levantamos dados e refletimos sobre o processo ensino-aprendizagem numa instância que vai além da observação do ocorrido no encontro presencial, articulando diferentes práticas e contextos. Estes registros permitem uma reconstrução das intenções, estratégias e pressupostos. A possibilidade de relatar, reler e partilhar os nossos escritos ultrapassa a reflexão sobre a nossa própria prática, pois se apresenta, também, como construção coletiva do trabalho docente.

Dessa forma, o trabalho desenvolvido na DOTE possibilitou o fortalecimento do processo de formação de grupos investigativos; visto que, neste escopo, os professores em formação continuada puderam vivenciar o uso de dinâmicas investigativas com o suporte da tecnologia educacional - AMEM.

\title{
BIBLIOGRAFIA
}

ANDER-EGG, E. Repensando la Investigación-acción-participativa: comentarios, críticas y sugerencias. México: El Ateneo, S. A. de C. V., 1990.

ANGULO RASCO, J. F. Investigacion-acción y curriculum: una nueva perspectiva en la investigación educativa. Investigación en la Escuela. Sevilha, n.11, p. 39-49, 1990. 
CARR, W \& KEMMIS, S. Teoría crítica de la enseñanza: la investigación-acción en la formación del profesorado. Barcelona: Martinez Roca, 1988.

$\mathrm{CARR}, \mathrm{W}$. Una teoría para la educación: Hacia una investigación educativa crítica. España, Madrid: Morata y Fundación Paideia, 1995.

DE BASTOS, F. P. \& GRABAUSKA, C. J. Investigação-ação educacional: possibilidade crítica e emancipatória na prática educativa. ? In: MION, R. A. \& SAITO, C.H. Investigação-ação: Mudando o trabalho de formar professores. Ponta Grossa: Gráfica Planeta, 2001.

DE BASTOS, F. P. \& MIQUELIN, A. F. Investigação-Ação Escolar e Meios Tecnológico-Comunicativos: Possíveis Potencialidades. Disponível em: $<$ http://amem.ce.ufsm.br/BIBLIOTECA/bibliografiadetalhes.php?cod_bib=320>. Acesso em: 10 jun. 2002.

DELIZOICOV, D. \& ANGOTTI, J. P. Metodologia do ensino de ciências. São Paulo: Cortez, 1990.

ELLIOT, J. What is Action-Research in Schools? Journal of Curriculum Studies, vol.10, n. 4, p. 335-7,1978.

Morata, 1991.

El cambio educativo desde la investigación-acción. España, Madrid:

FREIRE, P. Pedagogia do oprimido. SP: Paz e Terra, 1981.

. Pedagogia da autonomia: saberes necessários à prática educativa. $\mathrm{RJ}$ : Paz e Terra, 1996.

KEMMIS, S. \& MACTAGGART, R. Cómo planificar la Investigación-Acción. Barcelona: Laertes, 1988.

KEMMIS, S. La teoría de la práctica educativa (prólogo). In: CARR, W. Una teoría para la educación: Hacia una investigación educativa crítica. España, Madrid: Morata y Fundación Paideia, 1995.

MALLMANN, E. Monitorando as Tarefas Extra-Classe para Acoplar

Aprendizagens Presencial e a Distância. Projeto de Dissertação (Mestrado em Educação) - Universidade Federal de Santa Maria, Santa Maria, 2003.

TAUCHEN, G. et al. A investigação-ação educacional no contexto da escola pública e movimentos sociais. In: MION, R. A. \& SAITO, C.H. Investigação-ação: Mudando o trabalho de formar professores. Ponta Grossa: Gráfica Planeta, 2001.

TAUCHEN, G. O trabalho e os trabalhadores da educação de jovens e adultos. Linguagens \& Cidadania. Santa Maria, 9 ed., Jan/jun de 2003. Disponível em: <http://www.ufsm.br/linguagem_e_cidadania/01_3/index.html>. Acesso em: 10 set. 2003. 